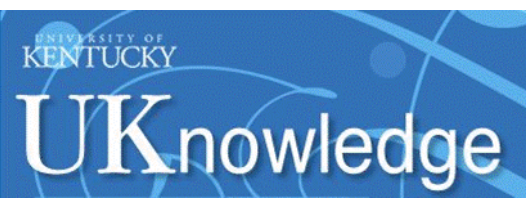

University of Kentucky

UKnowledge

8-10-2017

\title{
Lanthanum-Mediated Dehydrogenation of 1- and 2-Butynes: Spectroscopy and Formation of $\mathrm{La}\left(\mathrm{C}_{4} \mathrm{H}_{4}\right)$ Isomers
}

\author{
Wenjin Cao \\ University of Kentucky,wj.cao0707@uky.edu \\ Dilrukshi C. Hewage \\ University of Kentucky, hewagedilrukshi@gmail.com \\ Dong-Sheng Yang \\ University of Kentucky, dyang0@uky.edu
}

Follow this and additional works at: https://uknowledge.uky.edu/chemistry_facpub

Part of the Chemistry Commons, and the Physics Commons

Right click to open a feedback form in a new tab to let us know how this document benefits you.

\section{Repository Citation}

Cao, Wenjin; Hewage, Dilrukshi C.; and Yang, Dong-Sheng, "Lanthanum-Mediated Dehydrogenation of 1and 2-Butynes: Spectroscopy and Formation of $\mathrm{La}\left(\mathrm{C}_{4} \mathrm{H}_{4}\right)$ Isomers" (2017). Chemistry Faculty

Publications. 110.

https://uknowledge.uky.edu/chemistry_facpub/110

This Article is brought to you for free and open access by the Chemistry at UKnowledge. It has been accepted for inclusion in Chemistry Faculty Publications by an authorized administrator of UKnowledge. For more information, please contact UKnowledge@lsv.uky.edu. 


\section{Lanthanum-Mediated Dehydrogenation of 1- and 2-Butynes: Spectroscopy and Formation of $\mathrm{La}\left(\mathrm{C}_{4} \mathrm{H}_{4}\right)$ Isomers}

\section{Digital Object Identifier (DOI)}

https://doi.org/10.1063/1.4997567

\section{Notes/Citation Information}

Published in The Journal of Chemical Physics, v. 147, issue 6, 064303, p. 1-9.

This article may be downloaded for personal use only. Any other use requires prior permission of the author and AIP Publishing.

The following article appeared in The Journal of Chemical Physics, v. 147, issue 6, 064303, p. 1-9 and may be found at https://doi.org/10.1063/1.4997567. 


\title{
Lanthanum-mediated dehydrogenation of 1- and 2-butynes: Spectroscopy and formation of $\mathrm{La}\left(\mathrm{C}_{4} \mathrm{H}_{4}\right)$ isomers
}

\author{
Wenjin Cao, Dilrukshi Hewage, and Dong-Sheng Yang ${ }^{\text {a) }}$ \\ Department of Chemistry, University of Kentucky, Lexington, Kentucky 40506-0055, USA
}

(Received 24 May 2017; accepted 25 July 2017; published online 10 August 2017)

\begin{abstract}
La atom reactions with 1-butyne and 2-butyne are carried out in a laser-vaporization molecular beam source. Both reactions yield the same La-hydrocarbon products from the dehydrogenation and carbon-carbon bond cleavage and coupling of the butynes. The dehydrogenated species $\mathrm{La}\left(\mathrm{C}_{4} \mathrm{H}_{4}\right)$ is characterized with mass-analyzed threshold ionization (MATI) spectroscopy and quantum chemical computations. The MATI spectra of $\mathrm{La}\left(\mathrm{C}_{4} \mathrm{H}_{4}\right)$ produced from the two reactions exhibit two identical transitions, each consisting of a strong origin band and several vibrational intervals. The two transitions are assigned to the ionization of two isomers: $\mathrm{La}\left(\eta^{4}-\mathrm{CH}_{2} \mathrm{CCCH}_{2}\right)$ (Iso A) and $\mathrm{La}\left(\eta^{4}-\mathrm{CH}_{2} \mathrm{CHCCH}\right.$ ) (Iso $B$ ). The ground electronic states are ${ }^{2} A_{1}\left(C_{2 v}\right)$ for Iso $A$ and ${ }^{2} A\left(C_{1}\right)$ for Iso $B$. The ionization of the doublet state of each isomer removes a $\mathrm{La}$ 6s-based electron and results in a ${ }^{1} \mathrm{~A}_{1}$ ion of Iso $\mathrm{A}$ and a ${ }^{1} \mathrm{~A}$ ion of Iso B. The formation of Iso A from 2-butyne and Iso B from 1-butyne involves the addition of La to the $\mathrm{C} \equiv \mathrm{C}$ triple bond, the activation of two $\mathrm{C}\left(\mathrm{sp}^{3}\right)-\mathrm{H}$ bonds, and concerted elimination of a $\mathrm{H}_{2}$ molecule. The formation of Iso A from 1-butyne and Iso $\mathrm{B}$ from 2-butyne involves the isomerization of the two butynes to 1,2-butadiene in addition to the concerted $\mathrm{H}_{2}$ elimination. Published by AIP Publishing. [http://dx.doi.org/10.1063/1.4997567]
\end{abstract}

\section{INTRODUCTION}

Spectroscopic characterization of metal-hydrocarbon radicals or ions formed in gas phase reactions has recently attracted considerable attention. Metal ion-hydrocarbon species are largely investigated by infrared or ultravioletvisible photodissociation or photoelectron spectroscopy, ${ }^{1-20}$ whereas metal atom-hydrocarbons are mainly studied by photoexcitation or photoionization techniques. ${ }^{21-32}$ In principle, spectroscopic measurements could offer detailed information about metal-ligand bonding, molecular structures, and electronic states. These fundamental properties are vital for gaining insight into intrinsic reactivity patterns, reaction mechanisms, and structure-reactivity relationships of metal-hydrocarbon reactions. On the other hand, such measurements encounter substantial challenges because the metal-hydrocarbon radicals or ions are produced with a very low number density and often in an electronically open shell. We have recently reported the mass-analyzed threshold ionization (MATI) spectroscopy and formation of the metal-hydrocarbon radicals produced by the lanthanide-mediated $\mathrm{C}-\mathrm{C}$ and $\mathrm{C}-\mathrm{H}$ bond activation of small alkenes and alkynes. ${ }^{26-32}$ Our studies have demonstrated that the combination of the MATI spectroscopic measurements with theoretical computations is a powerful approach to the transient metal-hydrocarbon species.

Butyne $\left(\mathrm{C}_{4} \mathrm{H}_{6}\right)$ has four common linear isomers: 1butyne $\left(\mathrm{CH} \equiv \mathrm{CCH}_{2} \mathrm{CH}_{3}\right)$, 2-butyne $\left(\mathrm{CH}_{2} \mathrm{C} \equiv \mathrm{CCH}_{2}\right)$, 1,3butadiene $\left(\mathrm{H}_{2} \mathrm{C}=\mathrm{CHCH}=\mathrm{CH}_{2}\right)$, and 1,2-butadiene $\left(\mathrm{H}_{2} \mathrm{C}\right.$ $=\mathrm{C}=\mathrm{CCH}_{3}$ ). These isomers have been extensively studied

a) Author to whom correspondence should be addressed: dyang0@uky.edu with pyrolysis, ${ }^{33-35}$ photodissociation, ${ }^{36-38}$ and quantum chemical computations. ${ }^{39,40}$ The general consensus from those studies is that isomerization takes place before a thermal or photo-induced decomposition. Previous studies have also been reported on butyne reactions with transition metal atoms. Davis and co-workers studied 2-butyne reactions with early transition metal atoms $\left(\mathrm{M}=\mathrm{Y}, \mathrm{Zr}, \mathrm{Nb}, \mathrm{Mo}\right.$, and $\left.\mathrm{Mo}^{*}\right)$ using the crossed-molecular beam technique. ${ }^{41}$ In their study, $\mathrm{H}_{2}$, $\mathrm{CH}_{4}$, and $\mathrm{CH}_{3}$ elimination was observed for $\mathrm{Y}$, competition between $\mathrm{H}_{2}$ and $\mathrm{CH}_{4}$ elimination for $\mathrm{Zr}$ and $\mathrm{Nb}$, and only $\mathrm{H}_{2}$ elimination for Mo and Mo*. Although the early transition atoms are quite reactive toward 2-butyne, Mitchell and co-workers observed only a metal-ligand adduct from the $\mathrm{Ni}$ + 2-butyne reaction. ${ }^{42}$ To investigate reaction mechanisms, $\mathrm{Li}$ et al. and Ma et al. reported density functional theory (DFT) calculations on $\mathrm{Y}$ and $\mathrm{Nb}$ reactions with 2-butyne. ${ }^{43,44}$ The calculated potential energy profiles suggested that two possible isomers of $\mathrm{MC}_{4} \mathrm{H}_{4}(\mathrm{M}=\mathrm{Y}$ and $\mathrm{Nb})$ were $\mathrm{M}\left(\mathrm{HCCCCH}_{3}\right)$ and $\mathrm{M}\left(\mathrm{H}_{2} \mathrm{CCCCH}_{2}\right)$ formed preferably by concerted $\mathrm{H}_{2}$ eliminations.

We recently reported the spectroscopic characterization of the La reaction with one of the butyne isomers, 1,3-butadiene. We observed $\mathrm{La}\left(\mathrm{C}_{\mathrm{n}} \mathrm{H}_{\mathrm{n}}\right)\left(\mathrm{n}=2\right.$, 4, and 6) and $\mathrm{La}\left(\mathrm{C}_{\mathrm{m}} \mathrm{H}_{\mathrm{m}+2}\right)$ ( $\mathrm{m}=4$ and 6) with time-of-flight (TOF) mass spectrometry and investigated the structures and formation of several species using MATI spectroscopy and theoretical calculations. ${ }^{30}$ In this article, we report the La-mediated activation of two other isomers, 1-butyne and 2-butyne, by focusing on the structural identification and formation of the dehydrogenated species $\mathrm{La}\left(\mathrm{C}_{4} \mathrm{H}_{4}\right)$. The primary motivation is to examine if $\mathrm{La}\left(\mathrm{C}_{4} \mathrm{H}_{4}\right)$ produced by La reactions with 1-butyne, 2-butyne, and 1,3-butadiene has the same structure and if its 
formation involves an isomerization as reported by previous pyrolysis and photodissociation studies. To our knowledge, this is the first vibronic spectroscopic measurements of any metal radicals formed by the $\mathrm{C}-\mathrm{H}$ bond activation of 1 - and 2-butynes.

\section{EXPERIMENTAL AND COMPUTATIONAL METHODS}

The metal-cluster beam instrument used in this work consists of reaction and spectroscopy vacuum chambers and was described in a previous publication. ${ }^{45}$ Metal-hydrocarbon reactions were carried out in a laser-ablation metal cluster beam source. For the reaction of La with 1-butyne, 1-butyne $(98+\%$, Aldrich) was seeded in a He $(99.998 \%$, Scott Gross $)$ carrier gas with a 1-butyne:He molar ratio of $\sim 10^{-4}$ in a stainless steel mixing cylinder. La atoms were generated by pulsed-laser (Nd:YAG, Continuum Minilite II, $532 \mathrm{~nm}, 1.0$ $1.5 \mathrm{~mJ} /$ pulse) ablation of a La rod (99.9\%, Alfa Aesar) in the presence of the 1-butyne/carrier gas mixture (40 psi) delivered by a home-made piezoelectric pulsed valve. The metal atoms and gas mixture entered into a collision tube $(2 \mathrm{~mm}$ diameter and $2 \mathrm{~cm}$ length) and were then expanded into the reaction chamber, collimated by a cone-shaped skimmer ( $2 \mathrm{~mm}$ inner diameter), and passed through a pair of deflection plates. Ionic species in the molecular beam that were formed by laser ablation were removed by an electric field $\left(100 \mathrm{~V} \mathrm{~cm}^{-1}\right)$ applied on a pair of deflection plates, and neutral products were identified by photoionization TOF mass spectrometry. A separate experiment was carried out to confirm that 1-butyne was activated by La rather than the ablation laser. In this experiment, 1-butyne was introduced $3 \mathrm{~cm}$ downstream of the laser ablation point. The reaction products from this experiment were identical to those obtained from the experiment by passing the 1-butyne/He mixture through the ablation region, though a higher 1-butyne concentration was required to produce comparable ion intensities in the mass and MATI spectra. Because it bypassed the ablation region, laser excitation played no role in the 1-butyne activation. For the reaction of La with 2-butyne, 2-butyne (99\%, Sigma Aldrich), a liquid at the room temperature, was introduced $3 \mathrm{~cm}$ downstream of the laser ablation point, instead of premixed with the $\mathrm{He}$ gas.

Prior to the MATI measurements, photoionization efficiency spectra of $\mathrm{La}\left(\mathrm{C}_{4} \mathrm{H}_{4}\right)$ were recorded to locate an approximate ionization threshold to guide MATI scans. In the MATI experiment, $\mathrm{La}\left(\mathrm{C}_{4} \mathrm{H}_{4}\right)$ was excited to high-lying Rydberg states in a single-photon process and ionized by a delayed pulsed electric field. The excitation laser was the frequency doubled output of a tunable dye laser (Lumonics HD-500), pumped by the third harmonic output $(355 \mathrm{~nm})$ of a Nd:YAG laser (Continuum Surelite II). The laser beam was collinear and counter propagating with the molecular beam. The ionization pulsed field $\left(320 \mathrm{~V} \mathrm{~cm}^{-1}\right)$ was generated by two high voltage pulse generators (DEI, PVX-4140) and delayed by $\sim 20 \mu$ s from the laser pulse by a delayed pulsed generator (SRS, DG645). A small dc field $\left(6.0 \mathrm{~V} \mathrm{~cm}^{-1}\right)$ from a separate power supply (GW INSTEK, GPS-30300) was used to separate the ions produced by direct photoionization from the MATI ions generated by the delayed field ionization. The
MATI ion signal was obtained by scanning the wavelength of the tunable dye laser, detected by a dual microchannel plate detector, amplified by a preamplifier (SRS, SR445), visualized by a digital oscilloscope (Tektronix TDS 3012), and stored in a laboratory computer. Laser wavelengths were calibrated against titanium atomic transitions in the MATI spectral region, and the calibration was done after recording the MATI spectra. ${ }^{46}$ The Stark shift $(\Delta)$ in the adiabatic ionization energy (AIE) induced by the dc field $\left(\mathrm{E}_{\mathrm{f}}\right)$ was calculated using the relation of $\Delta \mathrm{AIE}=6.1 \mathrm{E}_{\mathrm{f}}^{1 / 2}$, where $\mathrm{E}_{\mathrm{f}}$ is in $\mathrm{V} \mathrm{cm}^{-1}$ and $\Delta \mathrm{AIE}$ is in $\mathrm{cm}^{-1} .47$

Computationally, DFT/B3LYP was used to calculate the equilibrium geometries and vibrational frequencies of various isomers of $\mathrm{La}\left(\mathrm{C}_{4} \mathrm{H}_{4}\right)$ and the free ligands. The basis sets used in these calculations were $6-311+G(d, p)$ for $\mathrm{C}$ and $\mathrm{H}$ and the Stuttgart/Dresden (SDD) effective-core-potential basis set with 28 electron core for La. We have extensively used the DFT/B3LYP method and found that this method generally produced adequate results for spectral and structural assignments of organometallic radicals. ${ }^{26-28,30-32,48}$ For each optimized stationary point, a vibrational analysis was performed to identify the nature of the stationary point (minimum or saddle point). In predicting reaction pathways, minima connected by a transition state were confirmed by intrinsic reaction coordinate calculations. Moreover, time-dependent (TD) DFT/B3LYP and equation-of-motion couple-cluster (EOM$\mathrm{CCSD})^{49}$ calculations were used to survey low-energy excited neutral doublet and ion singlet states. To refine the energies of the lowest doublet and singlet states, single-point energy calculations were carried out with the coupled cluster with single, double, and perturbative triple excitations $[\mathrm{CCSD}(\mathrm{T})]$ method involving the third-order Douglas-KrollHess scalar relativistic correction and at the DFT/B3LYP optimized geometries. Basis sets used in the $\operatorname{CCSD}(\mathrm{T})$ calculations were aug-cc-pVTZ-DK ${ }^{50,51}$ for $\mathrm{C}$ and $\mathrm{H}$ and cc-pVTZ-DK3 ${ }^{52}$ for La. The DFT, TDDFT, and EOM-CCSD calculations were performed with Gaussian 09 software package, ${ }^{53}$ whereas the $\operatorname{CCSD}(\mathrm{T})$ calculations were carried out with MOLPRO $2010.1 .^{54}$

To compare with the experimental MATI spectra, multidimensional Franck-Condon (FC) factors were calculated from the equilibrium geometries, harmonic vibrational frequencies, and normal coordinates of the neutral and ionized complexes. ${ }^{55}$ In these calculations, the recursion relations from Doktorov et al. ${ }^{56}$ were employed, and the Duschinsky effect ${ }^{57}$ was considered to account for a possible axis rotation from the neutral complex to the cation. Spectral simulations were obtained using the experimental line width and Lorentzian line shape. Transitions from excited vibrational levels of the neutral complex were considered by assuming thermal excitation at specific temperatures.

\section{RESULTS AND DISCUSSION}

\section{A. TOF mass spectra and La-hydrocarbon species}

Figure 1 displays the TOF mass spectra of the $\mathrm{La}+1$ butyne and La+2-butyne reactions recorded with $240 \mathrm{~nm}$ $\left(41667 \mathrm{~cm}^{-1}\right.$ or $\left.5.166 \mathrm{eV}\right)$ photoionization. The mass spectra show that the same La-hydrocarbon species are produced 


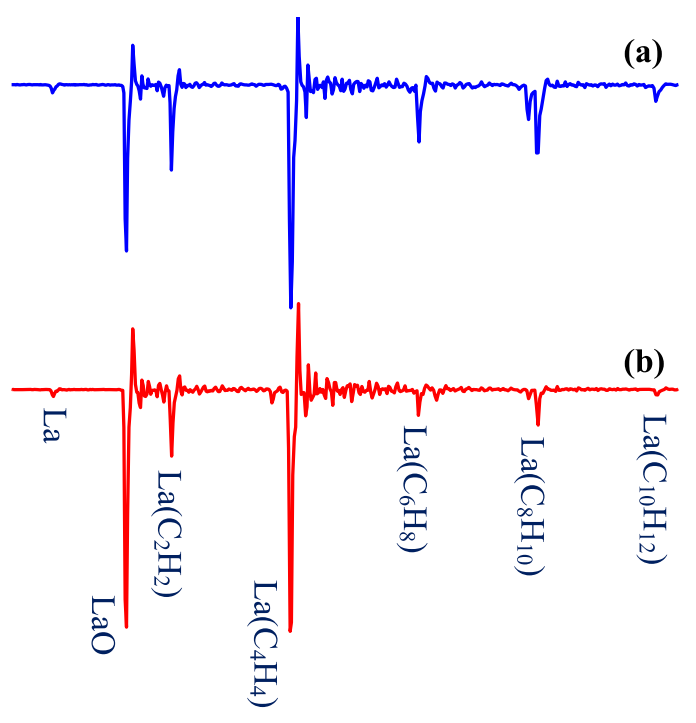

FIG. 1. TOF Mass spectra of $\mathrm{La}+1$-butyne (a) and $\mathrm{La}+2$-butyne (b) reactions recorded with $240 \mathrm{~nm}$ photoionization.

from the two reactions, which include $\mathrm{La}\left(\mathrm{C}_{\mathrm{n}} \mathrm{H}_{\mathrm{n}}\right)(\mathrm{n}=2$ and 4) and $\mathrm{La}\left(\mathrm{C}_{\mathrm{m}} \mathrm{H}_{\mathrm{m}+2}\right)(\mathrm{m}=6$ and 8$)$. The most prominent mass peak corresponding to a metal-hydrocarbon species is $\mathrm{La}\left(\mathrm{C}_{4} \mathrm{H}_{4}\right)$ formed by $\mathrm{H}_{2}$ elimination of the free ligands. Other metal-hydrocarbon species are $\mathrm{La}\left(\mathrm{C}_{2} \mathrm{H}_{2}\right)$ formed by $\mathrm{C}_{2} \mathrm{H}_{4}$ elimination, $\mathrm{La}\left(\mathrm{C}_{6} \mathrm{H}_{8}\right)$ possibly by $\mathrm{La}\left(\mathrm{C}_{2} \mathrm{H}_{2}\right)+\mathrm{C}_{4} \mathrm{H}_{6}$, and $\mathrm{La}\left(\mathrm{C}_{8} \mathrm{H}_{10}\right)$ by $\mathrm{La}\left(\mathrm{C}_{4} \mathrm{H}_{4}\right)+\mathrm{C}_{4} \mathrm{H}_{6}$. A similarly predominant dehydrogenated species [e.g., $\mathrm{Y}\left(\mathrm{C}_{4} \mathrm{H}_{4}\right)$ ] was also observed by Davis's group in their crossed-molecular-beam study of the $\mathrm{Y}+2$-butyne reaction, although the $\mathrm{C}-\mathrm{C}$ bond cleavage products [e.g., $\mathrm{Y}\left(\mathrm{C}_{3} \mathrm{H}_{3}\right)$ and $\mathrm{Y}\left(\mathrm{C}_{3} \mathrm{H}_{2}\right)$ ] were different. ${ }^{41}$ Previously, we studied the La reaction with 1,3-butadiene and observed a quite different product distribution. ${ }^{30}$ In the $\mathrm{La}+1$,3-butadiene reaction, $\mathrm{La}\left(\mathrm{C}_{2} \mathrm{H}_{2}\right)$ was the most abundant species, while $\mathrm{La}\left(\mathrm{C}_{4} \mathrm{H}_{4}\right)$ was only a minor one. Moreover, a $\mathrm{La}\left(\mathrm{C}_{4} \mathrm{H}_{6}\right)$ adduct was observed from the 1,3-butadiene reaction, which is absent from the butyne reactions. The considerably different product distributions suggest that the formation of the La-hydrocarbon radicals may take different pathways between the 1- and 2-butyene and 1,3-butadiene reactions. In this article, we focus on the characterization of the dehydrogenated species $\mathrm{La}\left(\mathrm{C}_{4} \mathrm{H}_{4}\right)$, which is observed in all three isomer reactions.

\section{B. MATI spectra and isomers of $\mathrm{La}\left(\mathrm{C}_{4} \mathrm{H}_{4}\right)$}

The MATI spectra of $\mathrm{La}\left(\mathrm{C}_{4} \mathrm{H}_{4}\right)$ from the $\mathrm{La}+1$-butyne and 2-butyne reactions are displayed in Figs. 2(a) and 2(b). Both spectra are essentially the same, and each consists of two band systems. The first band system originates at $41000(5) \mathrm{cm}^{-1}$. To the blue of this origin band, the spectrum shows a vibrational progression with up to three quanta of a vibrational mode with $386 \mathrm{~cm}^{-1}$, as well as bands at 301 and $616 \mathrm{~cm}^{-1}$, and a band at $687 \mathrm{~cm}^{-1}$ (marked with “*”) that is likely a combination band formed from the modes at 301 and $616 \mathrm{~cm}^{-1}$. To the red, a weak band at $354 \mathrm{~cm}^{-1}$ is also observed. The second band system exhibits the origin band at 41905 (5) $\mathrm{cm}^{-1}$, a vibrational progression of $326 \mathrm{~cm}^{-1}$ with up to two quanta, a weak band at $518 \mathrm{~cm}^{-1}$, and another weak

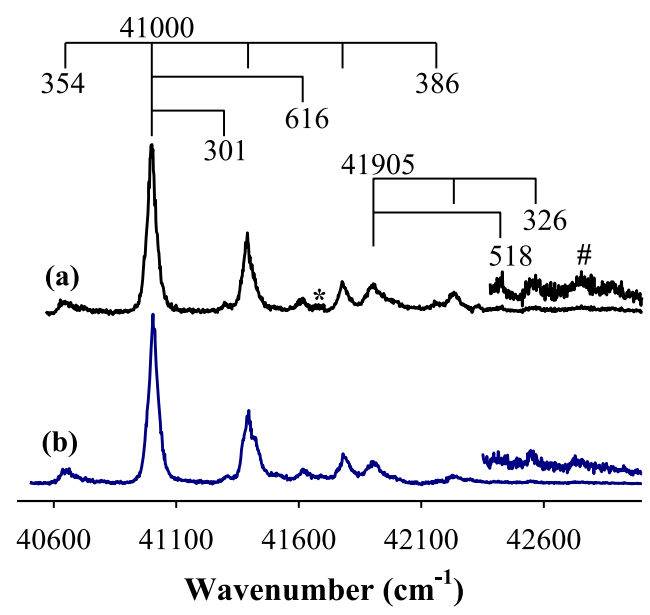

FIG. 2. MATI spectra of $\mathrm{La}\left(\mathrm{C}_{4} \mathrm{H}_{4}\right)$ formed from La reactions with 1-butyne (a) and 2-butyne (b).

band at $844 \mathrm{~cm}^{-1}$ (marked with "\#”) that is likely a combination band of 326 and $518 \mathrm{~cm}^{-1}$. The two band systems may arise from the ionization of one or two isomers. The same MATI spectra of $\mathrm{La}\left(\mathrm{C}_{4} \mathrm{H}_{4}\right)$ produced from both reactions suggest that this species may be formed through one or more common intermediates.

Figure 3 presents three possible isomers of $\mathrm{La}\left(\mathrm{C}_{4} \mathrm{H}_{4}\right)$ : $\mathrm{La}\left(\eta^{4}-\mathrm{CH}_{2} \mathrm{CCCH}_{2}\right)$ (Iso A), $\mathrm{La}\left(\eta^{4}-\mathrm{CH}_{2} \mathrm{CHCCH}\right.$ ) (Iso B), and $\mathrm{La}\left(\eta^{3}-\mathrm{CHCCCH}_{3}\right.$ ) (Iso C), along with the two butynes. In a simplistic view, Iso A may result from the 1,4hydrogen elimination of 2-butyne, Iso $B$ from the 3,4-hydrogen elimination of 1-butyne, and Iso C from either the 1,1dehydrogenation of 2-butyne or the 3,3-dehydrogenation of 1butyne. The $\mathrm{C}$ atomic numbering of Iso $\mathrm{B}$ is different from that of the free ligand 1-butyne because the 3,4-dehydrogenated hydrocarbon should be named 1-buten-3-yne (rather than 1butyn-3-ene) according to the standard nomenclature. At the CCSD(T)//B3LYP level, Iso A is predicted to be the most stable isomer, followed by Iso B at $1057 \mathrm{~cm}^{-1}$ and Iso C at $4937 \mathrm{~cm}^{-1}$. For the free ligands, 2-butyne is predicted to be more stable than 1-butyne by $1711 \mathrm{~cm}^{-1}$. The calculated energy difference between the two butyne isomers is comparable to the measured value of $1654 \mathrm{~cm}^{-1} .{ }^{33}$ For each of the three $\mathrm{La}\left(\mathrm{C}_{4} \mathrm{H}_{4}\right)$ isomers, the relative energies and molecular point groups of various spin states are summarized in Table I.

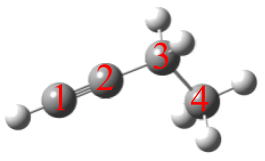

(a) 1-butyne

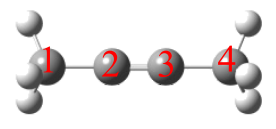

(b) 2-butyne

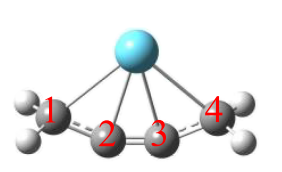

(c) Iso A

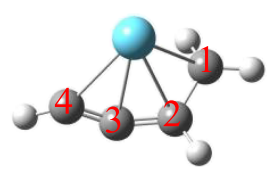

(d) Iso B

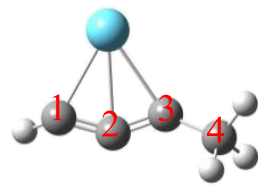

(e) Iso C
FIG. 3. Structures of 1-butyne (a), 2-butyne (b), $\mathrm{La}\left(\eta^{4}-\mathrm{CH}_{2} \mathrm{CCCH}_{2}\right.$ ) (Iso A) (c), $\mathrm{La}\left(\eta^{4}-\mathrm{CH}_{2} \mathrm{CHCCH}\right)$ (Iso B) (d), and $\mathrm{La}\left(\eta^{3}-\mathrm{CHCCCH}_{3}\right.$ ) (Iso C) (e). Relative energies of these species are listed in Table I. 
TABLE I. Point groups, electronic states, and relative energies $\left(\mathrm{E}, \mathrm{cm}^{-1}\right)$ of 1-butyne, 2-butyne, and three isomers of $\mathrm{La}\left(\mathrm{C}_{4} \mathrm{H}_{4}\right)$ from B3LYP and $\mathrm{CCSD}(\mathrm{T}) / / \mathrm{B} 3 \mathrm{LYP}$ calculations. The energy of 1-butyne is relative to that of 2-butyne, and the energies of $\mathrm{La}\left(\eta^{4}-\mathrm{CH}_{2} \mathrm{CHCCH}\right.$ ) (Iso B) and $\mathrm{La}\left(\eta^{3}-\mathrm{CHCCCH}_{3}\right.$ ) (Iso $\mathrm{C}$ ) are relative to that of $\mathrm{La}\left(\eta^{4}-\mathrm{CH}_{2} \mathrm{CCCH}_{2}\right.$ ) (Iso A). All energies include vibrational zero point corrections.

\begin{tabular}{lcccc}
\hline \hline Complex & Symmetry & State & $\mathrm{E}_{\mathrm{B} 3 \mathrm{LYP}}$ & $\mathrm{E}_{\mathrm{CCSD}(\mathrm{T}) / \mathrm{B} 3 \mathrm{LYP}}$ \\
\hline $\mathrm{La}\left(\eta^{4}-\mathrm{CH}_{2} \mathrm{CCCH}_{2}\right.$ ) (Iso A) & $\mathrm{C}_{2 \mathrm{v}}$ & ${ }^{2} \mathrm{~A}_{1}$ & 0 & 0 \\
& & ${ }^{4} \mathrm{~A}_{2}$ & 14164 & \\
& $\mathrm{C}_{2 \mathrm{v}}$ & ${ }^{1} \mathrm{~A}_{1}$ & 42749 & 41749 \\
& $\mathrm{C}_{2 \mathrm{v}}$ & ${ }^{3} \mathrm{~A}_{1}$ & 52178 & \\
$\mathrm{La}\left(\eta^{4}-\mathrm{CH}_{2} \mathrm{CHCCH}\right.$ ) (Iso B) & $\mathrm{C}_{1}$ & ${ }^{2} \mathrm{~A}$ & 1329 & 1057 \\
& $\mathrm{C}_{1}$ & ${ }^{4} \mathrm{~A}$ & 13524 & \\
& $\mathrm{C}_{1}$ & ${ }^{1} \mathrm{~A}$ & 43120 & 41870 \\
& $\mathrm{C}_{1}$ & ${ }^{3} \mathrm{~A}$ & 52075 & \\
La( $\eta^{3}-\mathrm{CHCCCH}_{3}$ ) (Iso C) & $\mathrm{C}_{1}$ & ${ }^{2} \mathrm{~A}$ & 4815 & 4937 \\
& $\mathrm{C}_{\mathrm{s}}$ & ${ }^{4} \mathrm{~A}^{\prime \prime}$ & 13010 & \\
& $\mathrm{C}_{1}$ & ${ }^{1} \mathrm{~A}$ & 47410 & 46601 \\
& $\mathrm{C}_{\mathrm{s}}$ & ${ }^{3} \mathrm{~A}^{\prime \prime}$ & 53291 & \\
2-butyne & $\mathrm{D}_{3 \mathrm{~h}}$ & ${ }^{1} \mathrm{~A}_{1}^{\prime}$ & 0 & 0 \\
1-butyne & $\mathrm{C}_{\mathrm{s}}$ & ${ }^{1} \mathrm{~A}^{\prime}$ & 2301 & 1711 \\
\hline \hline
\end{tabular}

The doublet and quartet states are for the neutral species, and the singlet and triplet states are for the corresponding singly charged cations. In each case, the doublet state is more stable than the quartet state, and the singlet state is more stable than the triplet state. Because the quartet state of each isomer is much higher (8000-12000 $\mathrm{cm}^{-1}$ at the B3LYP level) in energy than the doublet state, transition from this excited state is less likely to contribute to the observed spectrum. The ionization of the doublet state could lead to either singlet or triplet ions; however, the AIE of the triplet $\leftarrow$ doublet transition is predicted to be around $50000 \mathrm{~cm}^{-1}$ for each isomer, which is much higher than the energies of the experimental origin bands $\left(41000\right.$ or $41905 \mathrm{~cm}^{-1}$ ). Thus, the triplet $\leftarrow$ doublet transition can also be excluded from the observed spectrum.

The most likely assignments for the two band systems are the ${ }^{1} \mathrm{~A}_{1} \leftarrow{ }^{2} \mathrm{~A}_{1}$ transition of Iso $\mathrm{A}$ and the ${ }^{1} \mathrm{~A} \leftarrow{ }^{2} \mathrm{~A}$ transition of Iso $\mathrm{B}$. These assignments are supported by the excellent agreement between the measurements and computations, as shown in Table II and Fig. 4. Table II lists the measured and calculated the AIEs and vibrational frequencies, whereas Fig. 4 compares the observed spectrum [Fig. 4(a)] and simulations [Figs. 4(b) and 4(c)] of the singlet $\leftarrow$ doublet transitions of the three isomers. The origin bands in the simulations are aligned with those in the experimental spectrum [Fig. 4(a)], but the computed vibrational frequencies are unscaled in order to directly compare with the experimental spectrum. The ${ }^{1} \mathrm{~A}_{1}$ $\leftarrow{ }^{2} \mathrm{~A}_{1}$ transition of Iso A [Fig. 4(b), blue trace] matches nicely with the band system that originated at $41095 \mathrm{~cm}^{-1}$, and the ${ }^{1} \mathrm{~A} \leftarrow{ }^{2} \mathrm{~A}$ transition of Iso B [Fig. 4(b), red trace] reproduces the overall features of the band system that originated at 41000 $\mathrm{cm}^{-1}$. On the other hand, the ${ }^{1} \mathrm{~A} \leftarrow{ }^{2} \mathrm{~A}$ transition of Iso $\mathrm{C}$ [Fig. 4(c)] does not match with either of the two band systems; thus, this transition can be excluded from the MATI spectrum. The spectral signal of Iso $A$ is observed to be weaker than that of Iso B even though the former is predicted to be slightly more stable than the latter (Table I), similar to a recent study on the La-mediated dehydrogenation of propyne. ${ }^{26}$ At the first glance, the thermodynamic prediction is not consistent with the experimental observation. However, spectral intensities depend not only on the relative abundance of the two isomers in the molecular beams but also on the square of the transition moment integrals. Additionally, the relative abundance of the two isomers may be influenced by the pathways of the isomer formation.

For the $41905 \mathrm{~cm}^{-1}$ band system, the $326 \mathrm{~cm}^{-1}$ progression and the $518 \mathrm{~cm}^{-1}$ interval are attributed to the $\mathrm{La}^{+}-\mathrm{C}_{1,4}$ $\left(v_{7}{ }^{+}\right)$and $\mathrm{La}^{+}-\mathrm{C}_{2,3}\left(v_{6}{ }^{+}\right)$stretching vibrations in the ${ }^{1} \mathrm{~A}_{1}$ ion state of Iso $\mathrm{A}$, respectively. The higher frequency of the $\mathrm{La}^{+}-\mathrm{C}_{2,3}$ stretch than that of the $\mathrm{La}^{+}-\mathrm{C}_{1,4}$ stretching is consistent with the shorter $\mathrm{La}^{+}-\mathrm{C}_{2,3}$ bonds $(2.398 \AA$ ) than the $\mathrm{La}^{+}-\mathrm{C}_{1,4}$ bonds $(2.542 \AA$ ) (Table $\mathrm{S} 1$ of the supplementary material). For the $41000 \mathrm{~cm}^{-1}$ band system, the $386 \mathrm{~cm}^{-1}$ progression above the origin band is assigned to a $\mathrm{La}^{+}-\mathrm{C}_{2,4}$ stretch coupled with a $\mathrm{C}-\mathrm{H}$ out-of-plane bend $\left(\mathrm{v}_{19^{+}}\right)$excitation, the 301 and $616 \mathrm{~cm}^{-1}$ intervals are attributed to a $\mathrm{La}^{+}-\mathrm{C}_{1,4}$ stretch $\left(v_{20}{ }^{+}\right)$and a $\mathrm{C}_{2} \mathrm{C}_{3} \mathrm{C}_{4}$ bend coupled with a $\mathrm{CH}_{2}$ rock $\left(v_{15}{ }^{+}\right)$in the ${ }^{1} \mathrm{~A}$ ion state of Iso $\mathrm{B}$. The $354 \mathrm{~cm}^{-1}$ band below the origin band is due to the thermal excitation

TABLE II. Adiabatic ionization energies (AIEs, $\mathrm{cm}^{-1}$ ) and vibrational frequencies $\left(\mathrm{cm}^{-1}\right)$ of $\mathrm{La}\left(\eta^{4}\right.$ $-\mathrm{CH}_{2} \mathrm{CCCH}_{2}$ ) (Iso A) and $\mathrm{La}\left(\eta^{4}-\mathrm{CH}_{2} \mathrm{CHCCH}\right.$ ) (Iso B) from MATI spectroscopy and theoretical calculations. $v_{\mathrm{n}}$ and $v_{\mathrm{n}}{ }^{+}$are vibrational modes in the neutral and ionic states.

\begin{tabular}{lccc}
\hline \hline Complex & MATI & B3LYP & Mode description $^{\mathrm{a}}$ \\
\hline $\mathrm{La}\left(\eta^{4}-\mathrm{CH}_{2} \mathrm{CCCH}_{2}\right)\left(\right.$ Iso A), $\mathrm{C}_{2 \mathrm{v}},{ }^{1} \mathrm{~A}_{1} \leftarrow{ }^{2} \mathrm{~A}_{1}$ & \\
$\mathrm{AIE}$ & 41905 & $42749(41749)^{\mathrm{b}}$ & \\
$v_{6}^{+}$ & 518 & 515 & $\mathrm{La}-\mathrm{C}_{2} \mathrm{C}_{3}$ stretch \\
$v_{7}^{+}$ & 326 & 323 & $\mathrm{La}-\mathrm{C}_{1} \mathrm{C}_{4}$ stretch \\
$\mathrm{La}\left(\eta^{4}-\mathrm{CH}_{2} \mathrm{CHCCH}\right)\left(\right.$ Iso B), $\mathrm{C}_{1},{ }^{1} \mathrm{~A} \leftarrow{ }^{2} \mathrm{~A}$ & \\
$\mathrm{AIE}$ & 41000 & $41791(40813)^{\mathrm{b}}$ & \\
$v_{15}^{+}$ & 616 & 626 & $\mathrm{C}_{2} \mathrm{C}_{3} \mathrm{C}_{4}$ bend and $\mathrm{CH}$ rock \\
$v_{19}^{+} / v_{19}$ & $386 / 354$ & $386 / 348$ & $\mathrm{La}-\mathrm{C}_{2} \mathrm{C}_{4}$ stretch and C- $\mathrm{H}$ out-of-plane bend \\
$v_{20}^{+}$ & 301 & 285 & La- $\mathrm{C}_{1} \mathrm{C}_{4}$ stretch \\
\hline \hline
\end{tabular}

${ }^{\mathrm{a}}$ Carbon atomic numbering is shown in Fig. 3 .

${ }^{\mathrm{b}}$ The numbers in parentheses are from the $\operatorname{CCSD}(\mathrm{T}) / / \mathrm{B} 3 \mathrm{LYP}$ calculations. 


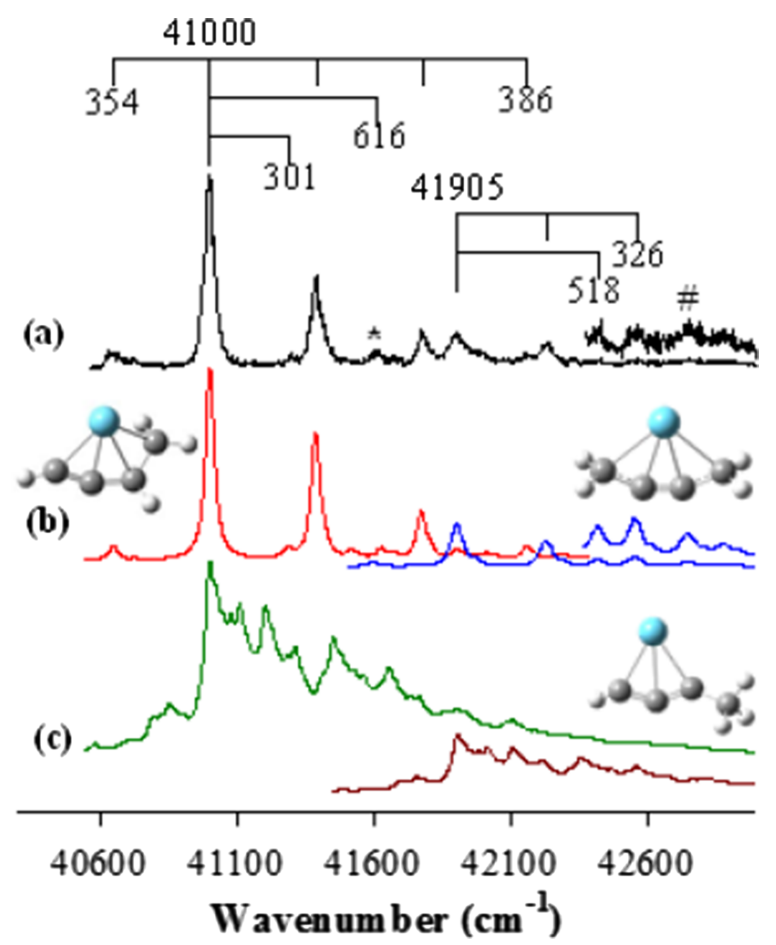

FIG. 4. MATI spectrum of $\mathrm{La}\left(\mathrm{C}_{4} \mathrm{H}_{4}\right)$ produced from $\mathrm{La}$ reactions with 1- and 2-butyne (a) and simulations of the ${ }^{1} \mathrm{~A}_{1} \leftarrow{ }^{2} \mathrm{~A}_{1}$ transition of $\mathrm{La}\left(\eta^{4}-\mathrm{CH}_{2} \mathrm{CCCH}_{2}\right.$ ) (Iso $\mathrm{A}$ ) (b, blue trace), the ${ }^{1} \mathrm{~A} \leftarrow{ }^{2} \mathrm{~A}$ transition of $\mathrm{La}\left(\eta^{4}-\mathrm{CH}_{2} \mathrm{CHCCH}\right.$ ) (Iso B) (b, red trace), and the ${ }^{1} \mathrm{~A} \leftarrow{ }^{2} \mathrm{~A}$ transition of $\mathrm{La}\left(\eta^{3}-\mathrm{CHCCCH}_{3}\right)($ Iso C) (c) at $200 \mathrm{~K}$.

of the La- $\mathrm{C}_{2,4}$ stretching mode $\left(v_{19}\right)$ in the ${ }^{2} \mathrm{~A}$ neutral state. In addition to these bands, the simulation of the $41000 \mathrm{~cm}^{-1}$ band system shows very weak transitions at 516 and $901 \mathrm{~cm}^{-1}$. The $516 \mathrm{~cm}^{-1}$ transition is too weak to be definitely identifiable in the experimental spectrum, although the spectrum may indicate a weak, broad signal around $510 \mathrm{~cm}^{-1}$. The $901 \mathrm{~cm}^{-1}$ transition overlaps with the origin band of the $41905 \mathrm{~cm}^{-1}$ system. The increased metal-ligand stretching frequency from $v_{19}$ to $v_{19}{ }^{+}$is due to the enhanced metal-ligand bonding induced by additional charge-multiple interactions in the ${ }^{1} \mathrm{~A}$ ion state. For both isomers, the MATI band systems exhibit short FC profiles because ionization removes a La-based $6 s^{1}$ electron. The experimental and theoretical AIEs and vibrational frequencies for the two isomers are summarized in Table II. It is clear from the table that the computed values are generally in very good agreement with the measured values. The computational errors on the AIEs are $\sim 800 \mathrm{~cm}^{-1}$ (or $\sim 2 \%$ ) at the B3LYP level and $\sim 200 \mathrm{~cm}^{-1}$ (or $\sim 0.5 \%$ ) at the $\operatorname{CCSD}(\mathrm{T}) / / \mathrm{B} 3 \mathrm{LYP}$ level. The theoretical frequencies also agree reasonably well with the experimental frequencies, with errors of $0-16 \mathrm{~cm}^{-1}$ (or $0 \%$ $5 \%$ ) at the B3LYP level. The CCSD(T) calculations of vibrational frequencies are not performed because such calculations are very time consuming with our computational facility, and the B3LYP results are sufficiently adequate for the vibrational assignments.

We have also investigated the transitions from excited doublet states and found that they are not associated with the observed MATI spectrum. Table S2 of the supplementary material summarizes the excited doublet and singlet states from the TDDFT and EOM-CCSD calculations. Three excited doublet and singlet states are located for each isomer. The excited doublet states are predicted to be $1.00 \pm 0.30 \mathrm{eV}$ above the ground state, and the excited singlet states are 2.30 $\pm 0.70 \mathrm{eV}$ above the lowest-energy singlet state. In addition to the high energies, the ionization energies of these doublet states do not match the observed values.

\section{Formation of $\mathrm{La}\left(\eta^{4}-\mathrm{CH}_{2} \mathrm{CCCH}_{2}\right)$ and $\mathrm{La}\left(\eta^{4}-\mathrm{CH}_{2} \mathrm{CHCCH}\right)$}

Figures 5 and 6 present the DFT/B3LYP computed stationary points for the formation of $\mathrm{La}\left(\eta^{4}-\mathrm{CH}_{2} \mathrm{CCCH}_{2}\right.$ ) (Iso A) and $\mathrm{La}\left(\eta^{2}-\mathrm{CH}_{2} \mathrm{CHCCH}\right)$ (Iso B) from the $\mathrm{H}_{2}$ elimination of 1-butyne and 2-butyne, respectively. These stationary points include reactants, intermediates (IMn), transition states (TSn), and products in their doublet spin states. Energies of the stationary points are also reported in Table S3 of the supplementary material. We focus on the concerted $\mathrm{H}_{2}$ elimination because previous studies have shown that step-wise dehydrogenation paths are less favorable for the metal atom-mediated dehydrogenation of small alkenes and alkynes. ${ }^{26,28,30-32,41,44,58-61}$

\section{1. $\mathrm{La}\left(\eta^{4}-\mathrm{CH}_{2} \mathrm{CCCH}_{2}\right)$ and $\mathrm{La}\left(\eta^{4}-\mathrm{CH}_{2} \mathrm{CHCCH}\right)$ from the isomerization and dehydrogenation of 1-butyne}

The dehydrogenation of 1-butyne takes three major steps to form Iso B (Fig. 5, black trace). The initial step is the formation of a $\pi$ complex [ $\mathrm{La}\left(\eta^{2}-\mathrm{CHCCH}_{2} \mathrm{CH}_{3}\right)$, IM1] through a La addition to the $\mathrm{C} \equiv \mathrm{C}$ triple bond. The $\pi$ complex has a metallacyclic structure (i.e., lanthanacyclopropene). Upon the La addition, the $\mathrm{C} \equiv \mathrm{C}$ triple bond of 1-butyne is elongated (by $0.14 \AA$ ) and becomes a double bond due to a loss of the $\pi$ character between the two $\mathrm{C}$ atoms. The change from $\mathrm{C} \equiv \mathrm{C}$ to $\mathrm{C}=\mathrm{C}$ is also evident from the bending of the butynylic $\mathrm{H}$ atom. A molecular orbital analysis reveals that the unpaired $\mathrm{p} \pi$ electron on each of the two $\mathrm{C}$ atoms is paired with a La $5 \mathrm{~d}$ electron to form a La- $\sigma$ bond. The resultant metallacyclopropene is the most stable species along the dehydrogenation pathway and is $52.4 \mathrm{kcal} \mathrm{mol}^{-1}$ more stable than the $\mathrm{La}+1$-butyne reactants (Table S3 of the supplementary material). The stabilization energy from $\mathrm{La}+1$-butyne to $\left[\mathrm{La}\left(\eta^{2}-\mathrm{CHCCH}_{2} \mathrm{CH}_{3}\right)\right.$, IM1] is similar to that of the corresponding propyne addition $\left(52.3 \mathrm{kcal} \mathrm{mol}^{-1}\right),{ }^{26}$ but it is much larger than that of the propene addition $\left(29.7 \mathrm{kcal} \mathrm{mol}^{-1}\right){ }^{31}$ Alkynes are generally better electrophiles due to their lower-energy empty $\mathrm{C}$ $\mathrm{p} \pi$ orbitals and tend to have stronger back electron donations than alkenes, which lead to shorter La-C bonds $(\sim 2.29 \AA)$ in the lanthanacyclopropenes than those in the lanthanacyclopropanes $(\sim 2.38 \AA)$. The second step (from IM1 to IM4) is the activation of a $\mathrm{C}\left(\mathrm{sp}^{3}\right)-\mathrm{H}$ bond of the $\mathrm{CH}_{2}$ group in the $\beta$ position. The $\mathrm{C}\left(\mathrm{sp}^{3}\right)-\mathrm{H}$ bond activation via TS1 involves a $\mathrm{CH}_{2}$ group rotation to bring a $\mathrm{H}$ atom to the proximity of the La atom (IM2). The associated $\mathrm{C}-\mathrm{H}$ bond of the $\mathrm{CH}_{2}$ in IM2 is elongated (by 17\%) compared to the same bond in IM1, and the $\mathrm{H}$ atom in the elongated $\mathrm{C}-\mathrm{H}$ bond continues to migrate toward the $\mathrm{La}$ atom to form a $\mathrm{La}-\mathrm{H}$ bond (IM3). IM3 is less stable than IM1 because the metal-hydrogen bond is weaker than the $\mathrm{C}-\mathrm{H}$ bond. Following the formation of the $\mathrm{La}-\mathrm{H}$ bond, the La-bound $\mathrm{H}$ atom in IM3 rotates away from the $-\mathrm{CHCH}_{3}$ group to free up a space for a second $\mathrm{C}-\mathrm{H}$ 


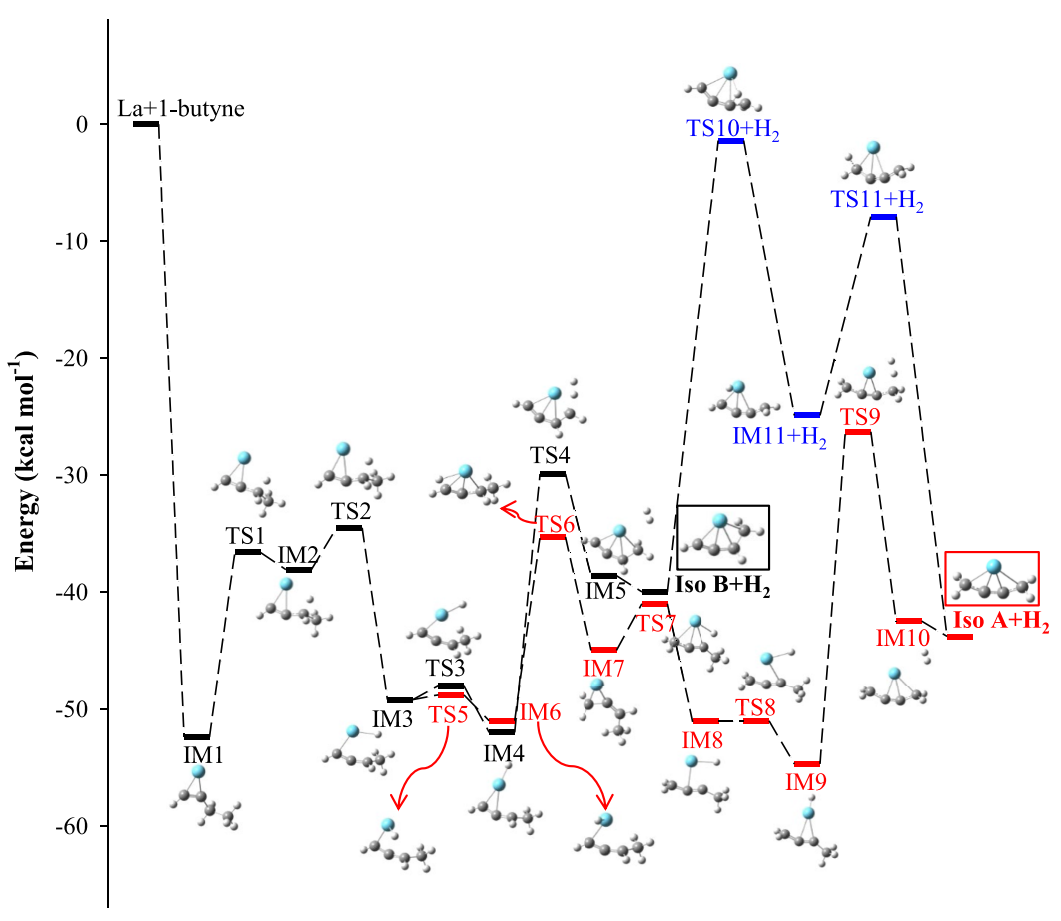

FIG. 5. Reaction pathways and energy profiles for the formation of $\mathrm{La}\left(\eta^{4}-\mathrm{CH}_{2} \mathrm{CCCH}_{2}\right.$ ) (Iso A) and $\mathrm{La}\left(\eta^{4}-\mathrm{CH}_{2} \mathrm{CHCCH}\right.$ ) (Iso B) from the $\mathrm{La}+1$-butyne reaction at the DFT/B3LYP level, where IMn stands for intermediates and TSn for transition states. bond activation (IM4). The rotational barrier (TS3) is small $\left(1.2 \mathrm{kcal} \mathrm{mol}^{-1}\right)$. Along with the $\mathrm{C}\left(\mathrm{sp}^{3}\right)-\mathrm{H}$ bond activation of the $\mathrm{CH}_{2}$ group, the activation of the butynylic $\mathrm{C}(\mathrm{sp})-\mathrm{H}$ bond could also occur. However, a $\mathrm{C}(\mathrm{sp})-\mathrm{H}$ bond is stronger than a $\mathrm{C}\left(\mathrm{sp}^{3}\right)-\mathrm{H}$ bond, and its activation is thermodynamically less favorable. The third step is the concerted $\mathrm{H}_{2}$ elimination via the activation of a $\mathrm{C}\left(\mathrm{sp}^{3}\right)-\mathrm{H}$ bond in the methyl group (TS4) and the formation of a dihydrogen complex (IM5). Because it is very weakly bound with the La atom, the removal of the $\mathrm{H}_{2}$ molecule from the metal atom has no energy barrier. In addition to the activation of a methyl $\mathrm{C}-\mathrm{H}$ bond, the second $\mathrm{C}-\mathrm{H}$ bond activation could also occur in the $\beta$ position of
IM4 because this bond is in a closer vicinity to the La atom than the methyl $\mathrm{C}-\mathrm{H}$ bond. However, the orbital character of the $\beta$ carbon atom is changed from $\mathrm{sp}^{3}$ to $\mathrm{sp}^{2}$ after the first $\mathrm{C}-\mathrm{H}$ bond cleavage, and a $\mathrm{C}\left(\mathrm{sp}^{2}\right)-\mathrm{H}$ bond is stronger than a $\mathrm{C}\left(\mathrm{sp}^{3}\right)-\mathrm{H}$ bond, making the $\mathrm{C}\left(\mathrm{sp}^{2}\right)-\mathrm{H}$ bond activation less favorable. The whole process of the $\mathrm{H}_{2}$ elimination of 1-butyne has no energy barriers and is exothermic by $40.0 \mathrm{kcal} \mathrm{mol}^{-1}$. Because the energy barriers (TS1-TS4) are so low compared with the total energy of the reactants $\mathrm{La}+1$-butyne, all intermediates (IM1-IM5) tend to be converted to the products. This may explain why no intermediates (including the most stable $\pi$ complex) were observed in our experiments even though they

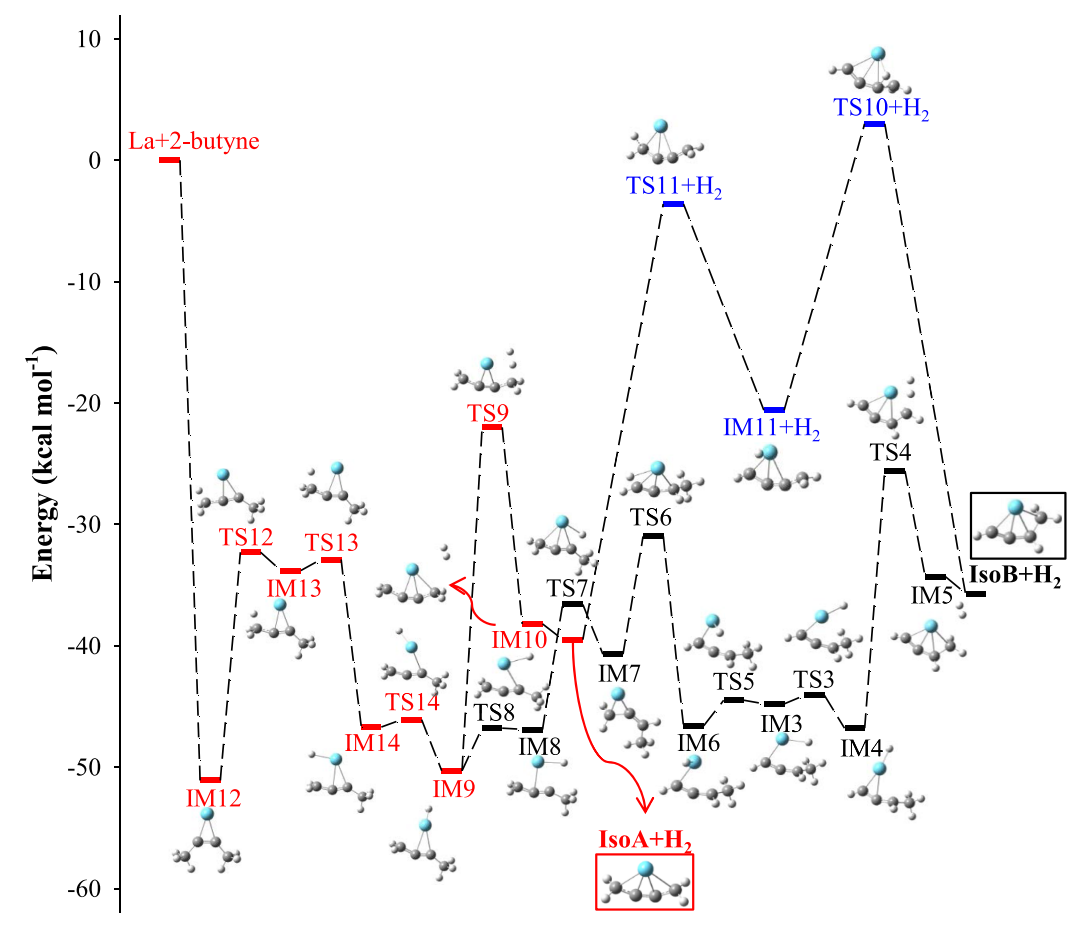

FIG. 6. Reaction pathways and energy profiles for the formation of $\mathrm{La}\left(\eta^{4}-\mathrm{CH}_{2} \mathrm{CCCH}_{2}\right.$ ) (Iso A) and $\mathrm{La}\left(\eta^{4}-\mathrm{CH}_{2} \mathrm{CHCCH}\right.$ ) (Iso $\mathrm{B}$ ) from the $\mathrm{La}+2$-butyne reaction at the DFT/B3LYP level, where IMn stands for intermediates and TSn for transition states. 
are more stable than the products. The current observation is similar to our previous studies of La reactions with ethylene, propene, and propyne. ${ }^{26,28,31}$

The formation of Iso $\mathrm{A}$ is more complicated due to the involvement of 1-butyne to 1,2-butadiene isomerization, which could precede the dehydrogenation (Fig. 5, black + red traces) or vice versa (Fig. 5, black + blue traces). In the first scenario, 1-butyne is isomerized to 1,2-butadiene via the $\mathrm{H}$ shift from $\mathrm{C} 3$ to $\mathrm{C} 1$, followed by the concerted $\mathrm{H}_{2}$ elimination from $\mathrm{C} 3$ and $\mathrm{C} 4$. The isomerization begins with the $\mathrm{La}$ addition (IM1) and insertion (IM2, IM3) as discussed above. From the inserted intermediate IM3, the La-bound $\mathrm{H}$ atom rotates to the vicinity of $\mathrm{C} 1$ (IM6) and then departs from La to connect with $\mathrm{C} 1$ to form $\mathrm{La}-(1,2$-butadiene) (IM7). The $\mathrm{La}-\mathrm{H}$ bond rotational barrier (TS5) is again small $\left(<1.0 \mathrm{kcal} \mathrm{mol}^{-1}\right)$, and the energies of IM3 and IM6 are similar because there is no bond formation or cleavage between the two intermediates. On the other hand, the barrier of the $\mathrm{H}$ shift from La to $\mathrm{C} 1$ is substantial $\left(15.5 \mathrm{kcal} \mathrm{mol}^{-1}\right)$ due to the cleavage of the $\mathrm{La}-\mathrm{H}$ bond. The resultant intermediate IM7 is a $\pi$ complex formed by La addition to 1,2-butadiene, which completes the process of the 1-butyne to 1,2-butadiene isomerization. From IM7, Iso A is formed by the dehydrogenation of 1,2-butadiene. The dehydrogenation involves the $\mathrm{La}$ insertion into the $\mathrm{C} 3-\mathrm{H}$ bond to form IM8, the La-bound $\mathrm{H}$ rotation to form IM9, the second $\mathrm{La}$ insertion into a $\mathrm{C} 4-\mathrm{H}$ bond to form a dihydrogen complex (IM10), and the concerted $\mathrm{H}_{2}$ elimination from the dihydrogen species to form Iso $\mathrm{A}$. The reaction pathway from $\mathrm{La}$ (1,2-butadien) (IM7) to Iso $\mathrm{A}$ is similar to that from $\mathrm{La}(1$-butyne) (IM1) to Iso $\mathrm{B}$, as both involve the $\beta-\mathrm{H}$ migration, $\mathrm{H}$ rotation, $\mathrm{C}\left(\mathrm{sp}^{3}\right)-\mathrm{H}$ activation, and concerted $\mathrm{H}_{2}$ elimination. The whole process (isomerization + dehydrogenation) has no energy barriers and is exothermic by $43.8 \mathrm{kcal} \mathrm{mol}^{-1}$. In the second scenario, Iso $\mathrm{A}$ is formed by the isomerization of Iso B (Fig. 5, blue). In this case, the $\mathrm{H}$ shift occurs after the dehydrogenation of 1butyne and encounters a substantially higher energy barrier (TS10). The second scenario is thus kinetically less favorable than the first one where the isomerization precedes the $\mathrm{H}_{2}$ elimination.

The reaction pathways described above involve the $\mathrm{La}-\mathrm{C}$ bond formation or breakage in several intermediates. Whether a $\mathrm{La}-\mathrm{C}$ bond is formed or broken in an intermediate is largely correlated with the coordination number of the relevant $\mathrm{C}$ atoms. For example, in IM2 $\mathrm{C} 1-\mathrm{C} 2$ is predicted to be close to a double bond (1.318 $\AA$ ) and $\mathrm{C} 2-\mathrm{C} 3$ to a single bond (1.422 $\AA$ ). To satisfy the usual coordination number (4) of a $\mathrm{C}$ atom, a bond is expected to form between $\mathrm{La}$ and each of the $\mathrm{C} 1$ and $\mathrm{C} 2$ atoms. The predicted metal-carbon distances are $2.346 \AA$ for $\mathrm{La}-\mathrm{C} 1$ and $2.433 \AA$ for $\mathrm{La}-\mathrm{C} 2$. On the other hand, both $\mathrm{C} 1-\mathrm{C} 2(1.286 \AA)$ and $\mathrm{C} 2-\mathrm{C} 3(1.341 \AA)$ in IM3 may be considered double bonds. Because it is already coordinately saturated, the $\mathrm{C} 2$ atom is unable to accommodate an additional bond, resulting in the $\mathrm{La}-\mathrm{C} 2$ bond cleavage. The weakened interaction between La and $\mathrm{C} 2$ is also evident from the elongated La-C2 distance from $2.433 \AA$ in IM2 to $2.623 \AA$ in IM3. Similar La-C bond formation or breaking in other intermediates could also be understood by considering the carbon coordination number.

\section{2. $\mathrm{La}\left(\eta^{4}-\mathrm{CH}_{2} \mathrm{CCCH}_{2}\right)$ and $\mathrm{La}\left(\eta^{4}-\mathrm{CH}_{2} \mathrm{CHCCH}\right)$ from the isomerization and dehydrogenation of 2-butyne}

The formation of Iso A through the $\mathrm{H}_{2}$ elimination of 2-butyne is similar to the formation of Iso B via the dehydrogenation of 1-butyne (Fig. 6, red trace). It involves the addition of La to the $\mathrm{C} \equiv \mathrm{C}$ bond to form a $\pi$ complex (IM12), the activation of a $\mathrm{C}-\mathrm{H}$ bond of the methyl group (IM12-IM14), the rotation of the $\mathrm{La}-\mathrm{H}$ bond (IM14-IM9), and the $\mathrm{C}-\mathrm{H}$ bond activation of another methyl group followed by concerted $\mathrm{H}_{2}$ elimination (IM9-IM10-Iso $\mathrm{A}+\mathrm{H}_{2}$ ). The last few steps (IM9IM10-Iso $\mathrm{A}+\mathrm{H}_{2}$ ) are identical to those of the Iso A formation from 1-butyne. The whole process has no energy barriers and is exothermic by $43.8 \mathrm{kcal} \mathrm{mol}^{-1}$. Two pathways for the formation of Iso B from 2-butyne are also similar to those of Iso A from 1-butyne. The first one (Fig. 6, red + black traces) involves the isomerization of 2-butyne to 1,2-butadiene (IM12-IM7) via the $\mathrm{H}$ shift from $\mathrm{C} 1$ to $\mathrm{C} 3$ (or $\mathrm{C} 4$ to $\mathrm{C} 2$ ) and the concerted $\mathrm{H}_{2}$ removal from 1,2-butadiene (IM7-Iso $\mathrm{B}+\mathrm{H}_{2}$ ). The dehydrogenation of 1,2-butadiene consists of the La insertion into a $\mathrm{C} 1-\mathrm{H}$ bond of the methylene group (IM7-IM6), the $\mathrm{La}-\mathrm{H}$ bond rotation (IM6-IM3-IM4), and the second La insertion into a $\mathrm{C} 4-\mathrm{H}$ bond of the methyl group (IM4-IM5) followed by the $\mathrm{H}_{2}$ elimination to Iso $\mathrm{B}+\mathrm{H}_{2}$ from IM5. The reaction path from IM7 to IM3 is the reversal of the formation of Iso A from 1-butyne (which is from IM3 to IM7), while the path from IM3 to Iso B is identical to the formation of Iso B from 1-butyne. The second pathway involves the isomerization of Iso A to Iso $\mathrm{B}$ through a $\mathrm{H}$ migration from $\mathrm{C} 1$ to $\mathrm{C} 3$ (Fig. 6, blue trace), which is the opposite to the isomerization of Iso $\mathrm{B}$ to Iso $\mathrm{A}$ in the 1-butyne reaction (Fig. 5, blue trace). Again, the Iso $\mathrm{A} \rightarrow$ Iso $\mathrm{B}$ isomerization is kinetically less favorable than 2-butyne $\rightarrow$ 1,2-butadien because of the higher energy barriers.

The common intermediate for the formation of Iso A in the 1-butyne reaction and Iso $B$ in the 2-buthyne reaction is La(1,2-butadiene) (IM7). The isomerization of 1- and 2butyne to 1,2-butadiene may explain the observation of the same products from the La reactions with both butynes. The $\mathrm{La}+1$ - and 2-butyne reactions are different from the $\mathrm{La}+1,3$ butadiene reaction, where only Iso B is observed and dehydrogenation does not involve the 1,3-butadiene $\rightarrow$ 1,2-butadiene isomerization. ${ }^{30}$

The 1- and 2-butyne $\rightarrow$ 1,2-butadiene isomerization was also reported by the previous thermal decomposition studies of the two butynes. ${ }^{33-35}$ In those studies, the fast isomerization of the butynes was proposed to take place before their decomposition. However, the isomerization mechanisms are different: it is induced by the metal mediation in the current work, while it took place through resonant radicals in the thermal decomposition.

\section{CONCLUSIONS}

We have reported the MATI spectroscopy and formation of $\mathrm{La}\left(\mathrm{C}_{4} \mathrm{H}_{4}\right)$ formed by the metal-mediated dehydrogenation of 1- and 2-butynes. The MATI spectra of $\mathrm{La}\left(\mathrm{C}_{4} \mathrm{H}_{4}\right)$ formed in both reactions exhibit the same two band systems, which are assigned to the ionization of two isomers: $\mathrm{La}\left(\eta^{4}-\mathrm{CH}_{2} \mathrm{CCCH}_{2}\right)\left(\mathrm{C}_{2 \mathrm{v}}\right)$ and $\mathrm{La}\left(\eta^{4}-\mathrm{CH}_{2} \mathrm{CHCCH}\right)\left(\mathrm{C}_{1}\right)$. 
The MATI measurements yield AIEs and metal-ligand stretching and ligand-based bending frequencies for the two isomers. The ground state of each isomer is a doublet state with a La-based $6 \mathrm{~s}^{1}$ electron configuration, and the lowest-energy state of the corresponding ion is a singlet state upon the removal of the La $6 \mathrm{~s}^{1}$ electron. Because of the non-bonding nature of the $\mathrm{La} 6 \mathrm{~s}^{1}$ electron, ionization has a very small effect on the geometry of the neutral state. Computed reaction paths and energy profiles suggest that the formation of the two isomers from the metal-mediated $\mathrm{H}_{2}$ elimination of 1- and 2-butynes share similar pathways. They consist of the initial addition of $\mathrm{La}$ to the $\mathrm{C} \equiv \mathrm{C}$ triple bond, the $\mathrm{H}$ atom shift from $\mathrm{C}\left(\mathrm{sp}^{3}\right)$ to $\mathrm{La}$, and the concerted $\mathrm{H}_{2}$ elimination for the formation of $\mathrm{La}\left(\eta^{4}-\mathrm{CH}_{2} \mathrm{CCCH}_{2}\right)$ from 2-butyne and $\mathrm{La}\left(\eta^{4}-\mathrm{CH}_{2} \mathrm{CHCCH}\right)$ from 1-butyne. Moreover, the isomerization of 1- and 2-butyne to 1,2-butadiene is involved in the formation of $\mathrm{La}\left(\eta^{4}-\mathrm{CH}_{2} \mathrm{CCCH}_{2}\right)$ from 1-butyne and $\mathrm{La}\left(\eta^{4}-\mathrm{CH}_{2} \mathrm{CHCCH}\right)$ from 2-butyne.

\section{SUPPLEMENTARY MATERIAL}

See supplementary material for the geometries of $\mathrm{La}\left(\eta^{4}-\mathrm{CH}_{2} \mathrm{CCCH}_{2}\right), \quad \mathrm{La}\left(\eta^{4}-\mathrm{CH}_{2} \mathrm{CHCCH}\right)$, and $\mathrm{La}\left(\eta^{3}\right.$ $\left.-\mathrm{CHCCCH}_{3}\right)$ in each of the lowest-energy spin states, the energies of their excited doublet and singlet states, and the energies of the stationary points along the reaction coordinates for the formation of $\mathrm{La}\left(\eta^{4}-\mathrm{CH}_{2} \mathrm{CCCH}_{2}\right)$ and $\mathrm{La}\left(\eta^{4}-\mathrm{CH}_{2} \mathrm{CHCCH}\right)$.

\section{ACKNOWLEDGMENTS}

We are grateful for the financial support from the National Science Foundation Division of Chemistry (Chemical Structure, Dynamics, and Mechanisms, Grant No. CHE-1362102). We also acknowledge additional support from the Kentucky Science and Engineering Foundation.

${ }^{1}$ R. S. Walters, T. D. Jaeger, and M. A. Duncan, J. Phys. Chem. A 106, 10482 (2002).

${ }^{2}$ R. S. Walters, E. D. Pillai, P. v. R. Schleyer, and M. A. Duncan, J. Am. Chem. Soc. 127, 17030 (2005).

${ }^{3}$ R. S. Walters, P. v. R. Schleyer, C. Corminboeuf, and M. A. Duncan, J. Am. Chem. Soc. 127, 1100 (2005).

${ }^{4}$ A. D. Brathwaite, T. B. Ward, R. S. Walters, and M. A. Duncan, J. Phys. Chem. A 119, 5658 (2015).

${ }^{5}$ J. A. Maner, D. T. Mauney, and M. A. Duncan, J. Phys. Chem. Lett. 6, 4493 (2015).

${ }^{6}$ R. B. Metz, Adv. Chem. Phys. 138, 331 (2008).

${ }^{7}$ G. Altinay, M. Citir, and R. B. Metz, J. Phys. Chem. A 114, 5104 (2010).

${ }^{8}$ G. Altinay and R. B. Metz, J. Am. Soc. Mass Spectrom. 21, 750 (2010).

${ }^{9}$ G. Altinay and R. B. Metz, Int. J. Mass Spectrom. 297, 41 (2010).

${ }^{10}$ M. Citir, G. Altinay, G. Austein-Miller, and R. B. Metz, J. Phys. Chem. A 114, 11322 (2010).

${ }^{11}$ G. Altinay, A. Kocak, J. S. Daluz, and R. B. Metz, J. Chem. Phys. 135, 084311 (2011).

${ }^{12}$ M. Perera, P. Ganssle, and R. B. Metz, Phys. Chem. Chem. Phys. 13, 18347 (2011).

${ }^{13}$ M. Perera, R. B. Metz, O. Kostko, and M. Ahmed, Angew. Chem., Int. Ed. 52, 888 (2013).

${ }^{14}$ A. Kocak, M. A. Ashraf, and R. B. Metz, J. Phys. Chem. A 119, 9653 (2015).

${ }^{15}$ A. Kocak, Z. Sallese, M. D. Johnston, and R. B. Metz, J. Phys. Chem. A 118, 3253 (2014).

${ }^{16}$ M. A. Ashraf, C. W. Copeland, A. Kocak, A. R. McEnroe, and R. B. Metz, Phys. Chem. Chem. Phys. 17, 25700 (2015).
${ }^{17}$ K. N. Reishus, A. D. Brathwaite, J. D. Mosley, and M. A. Duncan, J. Phys. Chem. A 118, 7516 (2014).

${ }^{18}$ V. J. F. Lapoutre, B. Redlich, A. F. G. van der Meer, J. Oomens, J. M. Bakker, A. Sweeney, A. Mookherjee, and P. B. Armentrout, J. Phys. Chem. A 117, 4115 (2013).

${ }^{19}$ O. W. Wheeler, M. Salem, A. Gao, J. M. Bakker, and P. B. Armentrout, J. Phys. Chem. A 120, 6216 (2016).

${ }^{20}$ S. R. Miller, T. P. Marcy, E. L. Millam, and D. G. Leopold, J. Am. Chem. Soc. 129, 3482 (2007).

${ }^{21}$ D. J. Brugh, R. S. Dabell, and M. D. Morse, J. Chem. Phys. 121, 12379 (2004).

${ }^{22}$ M. A. Garcia and M. D. Morse, J. Phys. Chem. A 117, 9860 (2013).

${ }^{23}$ D. J. Brugh and M. D. Morse, J. Chem. Phys. 141, 064304 (2014).

${ }^{24}$ E. L. Johnson and M. D. Morse, Mol. Phys. 113, 2255 (2015).

${ }^{25}$ M. A. Flory, A. J. Apponi, L. N. Zack, and L. M. Ziurys, J. Am. Chem. Soc. 132, 17186 (2010).

${ }^{26}$ D. Hewage, M. Roudjane, W. R. Silva, S. Kumari, and D.-S. Yang, J. Phys. Chem. A 119, 2857 (2015).

${ }^{27}$ D. Hewage, W. R. Silva, W. Cao, and D.-S. Yang, J. Am. Chem. Soc. 138, 2468 (2016).

${ }^{28}$ S. Kumari, W. Cao, Y. Zhang, M. Roudjane, and D.-S. Yang, J. Phys. Chem. A 120, 4482 (2016).

${ }^{29}$ Y. Zhang, M. W. Schmidt, S. Kumari, M. S. Gordon, and D.-S. Yang, J. Phys. Chem. A 120, 6963 (2016).

${ }^{30}$ D. Hewage, W. Cao, J. H. Kim, Y. Wang, Y. Liu, and D.-S. Yang, J. Phys. Chem. A 121, 1233 (2017).

${ }^{31}$ S. Kumari, W. Cao, D. Hewage, R. Silva, and D.-S. Yang, J. Chem. Phys. 146, 074305 (2017).

${ }^{32}$ D. Hewage, W. Cao, S. Kumari, R. Silva, T. H. Li, and D.-S. Yang, J. Chem. Phys. 146, 184304 (2017).

${ }^{33}$ Y. Hidaka, T. Higashihara, N. Ninomiya, H. Oshita, and H. Kawano, J. Phys. Chem. 97, 10977 (1993).

${ }^{34}$ Y. Hidaka, T. Higashihara, T. Oki, and H. Kawano, Int. J. Chem. Kinet. 27, 321 (1995).

${ }^{35}$ S. A. Chambreau, J. Lemieux, L. M. Wang, and J. S. Zhang, J. Phys. Chem. A 109, 2190 (2005).

${ }^{36}$ T. L. Bunn and T. Baer, J. Chem. Phys. 85, 6361 (1986).

${ }^{37}$ J. C. Robinson, W. Sun, S. A. Harris, F. Qi, and D. M. Neumark, J. Chem. Phys. 115, 8359 (2001).

${ }^{38}$ J. C. Robinson, S. A. Harris, W. Sun, N. E. Sveum, and D. M. Neumark, J. Am. Chem. Soc. 124, 10211 (2002).

${ }^{39}$ W. J. van der Hart, Int. J. Mass Spectrom. 208, 119 (2001).

${ }^{40}$ H. Y. Lee, V. V. Kislov, S. H. Lin, A. M. Mebel, and D. M. Neumark, Chem. Eur. J. 9, 726 (2003).

${ }^{41}$ R. Z. Hinrichs, J. J. Schroden, and H. F. Davis, J. Phys. Chem. A 112, 3010 (2008).

${ }^{42}$ S. A. Mitchell, M. A. Blitz, and R. Fournier, Can. J. Chem. 72, 587 (1994).

${ }^{43}$ T. H. Li, C. M. Wang, S. W. Yu, X. Y. Liu, H. Fu, and X. G. Xie, J. Mol. Struct.: THEOCHEM 915, 105 (2009).

${ }^{44}$ P.-P. Ma, Y.-C. Wang, W.-X. Wang, Z.-P. Deng, G.-P. Niu, X.-L. Wang, S. Li, and Y.-W. Zhang, Comput. Theor. Chem. 1085, 23 (2016).

${ }^{45}$ B. R. Sohnlein, S. G. Li, J. F. Fuller, and D.-S. Yang, J. Chem. Phys. 123, 014318 (2005).

${ }^{46}$ C. E. Moore, Atomic Energy Levels (National Bureau of Standards, Washington, DC, 1971).

${ }^{47}$ M. A. Duncan, T. G. Dietz, and R. E. Smalley, J. Chem. Phys. 75, 2118 (1981).

${ }^{48}$ D.-S. Yang, J. Phys. Chem. Lett. 2, 25 (2011).

${ }^{49}$ P. Piecuch, J. R. Gour, and M. Wloch, Int. J. Quantum Chem. 109, 3268 (2009).

${ }^{50}$ T. H. Dunning, Jr., J. Chem. Phys. 90, 1007 (1989).

${ }^{51}$ W. A. de Jong, R. J. Harrison, and D. A. Dixon, J. Chem. Phys. 114, 48 (2001).

${ }^{52}$ Q. Lu and K. A. Peterson, J. Chem. Phys. 145, 054111 (2016).

${ }^{53}$ M. J. Frish, G. W. Trucks, H. B. Schlegel, G. E. Scuseria, M. A. Robb, J. R. Cheeseman, G. Scalmani, V. Barone, B. Mennucci, G. A. Petersson, H. Nakatsuji, M. Caricato, X. Li, H. P. Hratchian, A. F. Izmaylov, J. Bloino, and G. Zheng, GaUssian 09, Revision A.01 (Gaussian, Inc., Wallingford, CT, 2009).

${ }^{54}$ P. J. K. H.-J. Werner, F. R. Manby, M. Schütz, P. Celani, G. Knizia, T. Korona, R. Lindh, A. Mitrushenkov, G. Rauhut, T. B. Adler, R. D. Amos, A. Bernhardsson, A. Berning, D. L. Cooper, M. J. O. Deegan, A. J. Dobbyn, F. Eckert, E. Goll, C. Hampel, A. Hesselmann, G. Hetzer, T. Hrenar, G. Jansen, C. Köppl, Y. Liu, A. W. Lloyd, R. A. Mata, A. J. May, 
S. J.McNicholas, W. Meyer, M. E. Mura, A. Nicklass, P. Palmieri, K. Pflüger, R. Pitzer, M. Reiher, T. Shiozaki, H. Stoll, A. J. Stone, R. Tarroni, T. Thorsteinsson, M. Wang, and A. Wolf, molpro, version 2010.1, a package of $a b$ initio programs, 2010, see http://www.molpro.net.

${ }^{55} \mathrm{~S}$. Li, "Threshold photoionization and ZEKE photoelectron spectroscopy of metal complexes," Ph.D. thesis, University of Kentucky, 2004.

${ }^{56}$ E. V. Doktorov, I. A. Malkin, and V. I. Man'ko, J. Mol. Spectrosc. 64, 302 (1977).
${ }^{57}$ F. Duschinsky, Acta Physicochim. 7, 551 (1937).

${ }^{58}$ Y. Wen, M. Porembski, T. A. Ferrett, and J. C. Weisshaar, J. Phys. Chem. A 102, 8362 (1998).

${ }^{59}$ M. Porembski and J. C. Weisshaar, J. Phys. Chem. A 105, 6655 (2001).

${ }^{60}$ R. Z. Hinrichs, J. J. Schroden, and H. F. Davis, J. Phys. Chem. A 107, 9284 (2003).

${ }^{61}$ T. H. Li and X. G. Xie, J. Phys. Org. Chem. 23, 768 (2010). 


\section{Lanthanum-mediated dehydrogenation of 1- and 2-butynes: Spectroscopy and formation of $\mathrm{La}\left(\mathrm{C}_{\mathbf{4}} \mathrm{H}_{4}\right)$ isomers}

Wenjin Cao, Dilrukshi Hewage, and Dong-Sheng Yang

Citation: The Journal of Chemical Physics 147, 064303 (2017); doi: 10.1063/1.4997567

View online: https://doi.org/10.1063/1.4997567

View Table of Contents: http://aip.scitation.org/toc/jcp/147/6

Published by the American Institute of Physics

\section{Articles you may be interested in}

Spectroscopy and formation of lanthanum-hydrocarbon radicals formed by $\mathrm{C}-\mathrm{C}$ bond cleavage and coupling of propene

The Journal of Chemical Physics 146, 184304 (2017); 10.1063/1.4982949

Precision measurement of electron affinity of $\mathrm{Zr}$ and fine structures of its negative ions

The Journal of Chemical Physics 147, 064306 (2017); 10.1063/1.4986547

Binding energies of hydrated cobalt hydroxide ion complexes: A guided ion beam and theoretical investigation

The Journal of Chemical Physics 147, 064305 (2017); 10.1063/1.4991557

The collision-free photochemistry of methyl azide at $157 \mathrm{~nm}$ : Mechanism and energy release

The Journal of Chemical Physics 147, 064307 (2017); 10.1063/1.4997783

Lanthanum-mediated dehydrogenation of butenes: Spectroscopy and formation of $\mathrm{La}\left(\mathrm{C}_{4} \mathrm{H}_{6}\right)$ isomers

The Journal of Chemical Physics 148, 044312 (2018); 10.1063/1.5017615

Mass-analyzed threshold ionization spectroscopy of lanthanum-hydrocarbon radicals formed by $\mathrm{C}-\mathrm{H}$ bond activation of propene

The Journal of Chemical Physics 146, 074305 (2017); 10.1063/1.4976316

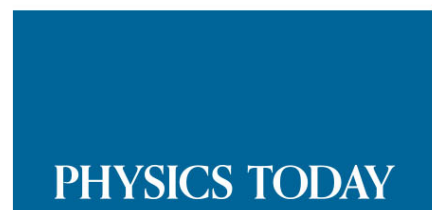

WHITEPAPERS
ADVANCED LIGHT CURE ADHESIVES

Take a closer look at what these environmentally friendly adhesive systems can do
READ NOW

PRESENTED BY

(8) MASTERBOND' 